\title{
EXTRAÇÃO POR PONTO NUVEM: TÉCNICA ALTERNATIVA PARA A EXTRAÇÃO DE RESÍDUOS DE AGROTÓXICOS
}

\author{
ANÍZIO M. FARIA* \\ MARIA ELIANA L. R. QUEIROZ** \\ ANTÔNIO A. NEVES ${ }^{* * *}$
}

\begin{abstract}
Este trabalho apresenta breve revisão da aplicação de soluções aquosas de surfactantes (extração por ponto nuvem) para a extração e a pré-concentração de agrotóxicos como alternativa promissora às técnicas convencionais de extração. Os fundamentos da extração por ponto nuvem, bem como sua capacidade de solubilizar compostos orgânicos e o protocolo experimental para a extração de diferentes classes de agrotóxicos em matrizes sólidas e líquidas foram descritos. Também foram abordados os problemas práticos e a perspectiva dessa técnica quando empregada como etapa que antecede as análises por métodos cromatográficos e eletroforéticos. Apesar dos avanços obtidos até o momento será necessário estudar em maior profundidade as aplicações dessa metodologia na extração de agrotóxicos de amostras de solo, folhas e frutos. Novos estudos também devem ser conduzidos para ampliar o campo de aplicação da extração por ponto nuvem para a eletroforese capilar em meio orgânico, eletrocromatografia e cromatografia a gás com detecção por espectrometria de massas. Sugerese ainda como campo de investigação em potencial a automação da técnica de extração por ponto nuvem e seu acoplamento on-line com o sistema de operação.
\end{abstract}

PALAVRAS-CHAVE: EXTRAÇÃO POR PONTO NUVEM; AGROTÓXICOS; TÉCNICAS DE EXTRAÇÃO.

* Doutorando em Química, Universidade Estadual de Campinas, Campinas, SP (email: anizio@iqm.unicamp.br).

* $\quad$ Professora, Doutora em Química Analítica, Departamento de Química, Universidade Federal de Viçosa (UFV), Viçosa, MG.

*** Professor, Doutor em Solos e Nutrição de Plantas, Departamento de Química, UFV, Viçosa, MG. 


\section{INTRODUÇÃO}

Um dos principais fatores de poluição do solo, subsolo e águas doces é a utilização abusiva de agrotóxicos nas lavouras. A média anual brasileira de uso de agrotóxicos nas lavouras é duas vezes superior à do resto do mundo, sendo a classe de inseticidas organofosforados uma das mais empregadas (SCORZA JÚNIOR et al., 2000). O uso desses produtos ocorre, normalmente, de forma indiscriminada resultando num acúmulo de resíduos nos alimentos, nas águas e no solo.

O monitoramento dos resíduos de agrotóxicos nos solos e em águas tem se tornado imprescindível para a redução do impacto ambiental, sendo realizado pela determinação e quantificação desses resíduos. Os métodos usados na análise de resíduos de agrotóxicos em matrizes como água, solo, folha e fruto exigem, em geral, que se efetue a priori extração e muitas vezes pré-concentração desses compostos. Os métodos oficiais recomendam extrações clássicas com solventes, como a extração líquido-líquido (ELL) e a extração líquido-sólido (ELS) (KOVAI, PROSEN e ZUPANI-KRALJ, 2004), devido à facilidade de manuseio e a simplicidade dos equipamentos. Porém, a ELL envolve grandes quantidades de solventes comumente tóxicos e de alto custo, além de elevado tempo de análise, formação de emulsões e falta de sensibilidade para analitos mais voláteis (SICÍLIA et al., 1999; QUINA e HINZE, 1999; MARTINEZ et al., 2000). A extração em fase sólida (EFS), embora apresente algumas vantagens em relação a ELL, tem como desvantagens a saturação dos sítios adsorventes resultando na diminuição do fluxo de solvente pelo cartucho, falta de reprodutibilidade e, em muitos casos, a não reutilização dos cartuchos (MAHARA, BOROSSAY e TORKOS, 1998).

Nas últimas décadas, o desenvolvimento de metodologias de extração tem sido bastante explorado com o intuito de minimizar ou até mesmo eliminar os problemas relacionados com as técnicas convencionais. Métodos alternativos vêm sendo aplicados com sucesso na extração de agrotóxicos como, por exemplo, extração por membrana (membrane extraction = ME) (XU et al., 2002), microextração em fase sólida (solid phase microextraction = SPME) (DERYABINA et al., 2005) e microextração líquido-líquido (liquid-liquid microextraction = LLM) (ZHU et al., 2002).

Atenção considerável vem sendo dedicada ao uso de micelas de surfactantes para préconcentração e separações em química analítica e nas ciências da separação (PRAMAURO e PELIZZETTI, 1988; MCINTIRE, 1990). Soluções aquosas de certas micelas de surfactantes exibem comportamento de separação de fases com rápida turbidez da solução em função da alteração da temperatura. A temperatura em que esse fenômeno ocorre é conhecida como temperatura de ponto nuvem. Tal fenômeno vem sendo explorado nas ciências da separação para o desenvolvimento de metodologias de extração, purificação e esquemas de pré-concentração para diferentes classes de compostos, dentre as quais destacam-se os agrotóxicos. O referido método torna-se conveniente por exigir adição de pequena quantidade de surfactante na solução aquosa da amostra, eliminando a necessidade do uso de grandes quantidades de solventes orgânicos como na extração líquido-líquido convencional (QUINA e HINZE, 1999; MARTINEZ et al., 2000). Essa metodologia é conhecida como extração por ponto nuvem (cloud point extraction $=\mathrm{CPE}$ ) ou extração intermediada por micelas (micellemediated extraction). Sua aplicação analítica está condicionada à qualquer componente presente na água que seja capaz de se associar às micelas, ou de ser dissolvido em seu interior orgânico (que atua como fase pseudo-orgânica).

Este trabalho descreve os fundamentos da técnica de extração por ponto nuvem e suas recentes aplicações, com ênfase na extração e pré-concentração de agrotóxicos de diferentes matrizes.

\subsection{SISTEMAS MICELARES}

A palavra surfactante, simplificação do termo "agente ativo de superfície", refere-se à classe de compostos químicos conhecidos como anfifílicos (do grego, "não tem certeza do que gostam"), em que uma das partes (a cabeça) é polar ou hidrofílica e a outra (a cauda) hidrofóbica. A última parte é, 
geralmente, uma cadeia de hidrocarbonetos com números diferentes de átomos de carbono, podendo ser linear ou ramificada (PRAMAURO e PELIZZETTI, 1988).

Os surfactantes são classificados como iônicos (com cargas positivas ou negativas nas moléculas), não-iônicos (não apresentam cargas) ou zwitteriônicos (com cargas positiva e negativa na molécula). Em solução aquosa, e em baixas concentrações, moléculas de surfactantes são encontradas na forma de monômeros, embora dímeros e trímeros também estejam presentes (MARTINEZ et al., 2000).

Os surfactantes não-iônicos podem formar micelas (agrupamentos dinâmicos de moléculas de tamanho coloidal) quando a concentração é aumentada até certo valor limiar, chamado de concentração micelar crítica (cmc) (FRÖSCHL, STANGL e NIESSNER, 1997). Esses agregados (micelas), contendo entre 30 e 500 monômeros (referidos como número de agregação, N), estão em equilíbrio na solução com concentração de surfactante próxima da cmc. O processo de agregação dos monômeros de surfactantes, que resulta na formação das micelas, ainda não está bem claro. Dependendo, sobretudo, da especificidade do surfactante e das condições da solução, as micelas podem adotar diversas formas (de esférica a elipsoidal). No caso dos surfactantes mais comuns, a região interior da micela contém a parte hidrofóbica da molécula de surfactante. Já a superfície exterior consiste em grupos hidrofílicos hidratados ligados por moléculas de água (MARTINEZ et al., 2000).

Sob o ponto vista analítico, uma das propriedades mais importantes dessas estruturas organizadas é a sua capacidade de solubilizar analitos com diferentes características e naturezas. Tais solutos podem interagir eletrostaticamente, hidrofobicamente ou pela combinação desses dois efeitos (Figura 1).

\section{FIGURA 1 - POSSÍVEIS INTERAÇÕES ENTRE O ANALITO E A MICELA DE SURFACTANTE}

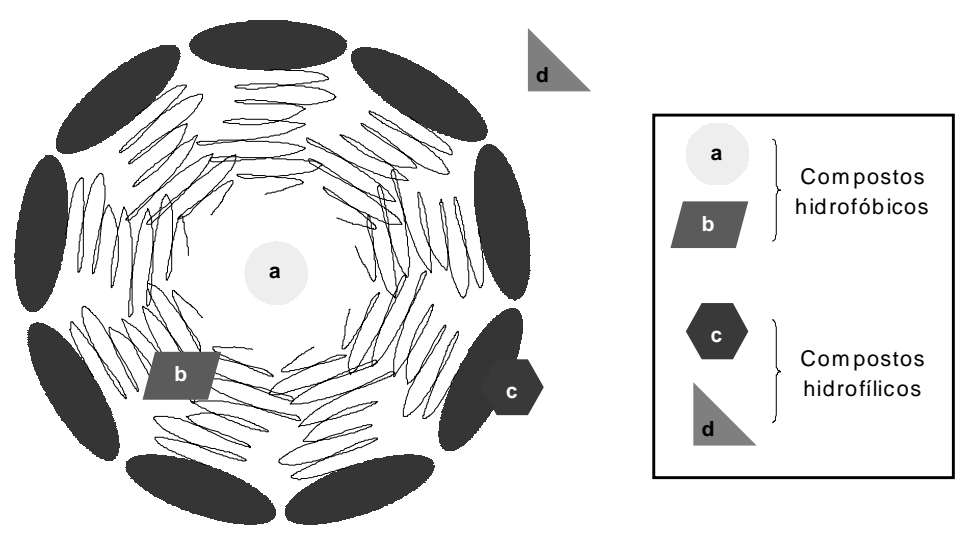

Quaisquer componentes, presentes originalmente em solução, que sejam capazes de se ligarem ou serem dissolvidos no interior hidrofóbico do agregado micelar pode ser extraído da solução original e concentrado em pequeno volume da fase rica em surfactante. A extensão da extração depende muito da força de interação entre o soluto e a micela (HINZE e PRAMAURO, 1993; FRÖSCHL, STANGL e NIESSNER, 1997).

QUINA, ALONSO e FARAH (1995) encontraram a relação entre a constante de equilíbrio para a incorporação do soluto na fase micelar e diferentes parâmetros, como hidrofobicidade, capacidade de formar ligações de hidrogênio, refração molar e dipolaridade. Além da estrutura do soluto, outros fatores como a estrutura do surfactante e a temperatura também estão envolvidos no processo de solubilização de solutos orgânicos no interior das micelas. 


\subsection{SEPARAÇÃO DE FASES}

Ao aquecer solução micelar de surfactante não-iônico acima da temperatura do ponto nuvem, o sistema (inicialmente, contendo uma fase isotrópica) separa-se em duas fases isotrópicas. Uma delas é rica em surfactante e a outra aquosa (solução diluída de surfactante) contém concentração do surfactante inferior a cmc. Ao serem separadas, a fase rica em surfactante pode carregar consigo as moléculas apolares presentes na amostra aquosa como representado esquematicamente na Figura 2. O fenômeno é reversível e sob resfriamento, uma única fase é novamente obtida. A separação das fases resulta da competição entre entropia, que favorece a miscibilidade das micelas em água, e entalpia, que favorece a separação das micelas da água. A variação de ambas com a temperatura pode resultar num ponto consoluto, no qual os dois processos atuam com a mesma amplitude. A separação de fases ocorre em estreita faixa de temperatura (QUINA e HINZE, 1999; MARTINEZ et al., 2000; HINZE e PRAMAURO, 1993; QUINA, ALONSO e FARAH al., 1995).

\section{FIGURA 2 - PROCESSO DE SEPARAÇÃO DE FASES PELA METODOLOGIA DE EXTRAÇÃO POR PONTO NUVEM}

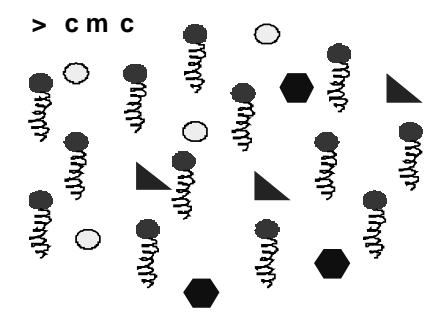

Amostra + surfactante

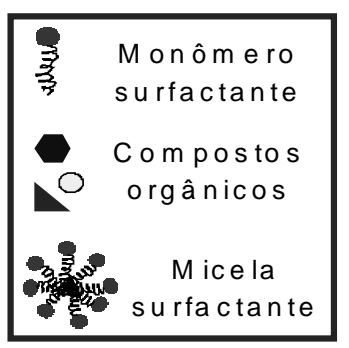

$>$ tem peratura crítica
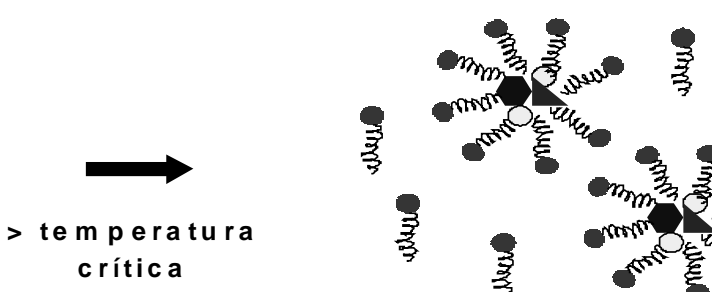

芕

桑

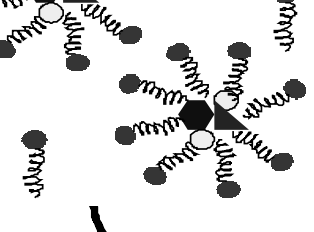

$>$ tempo
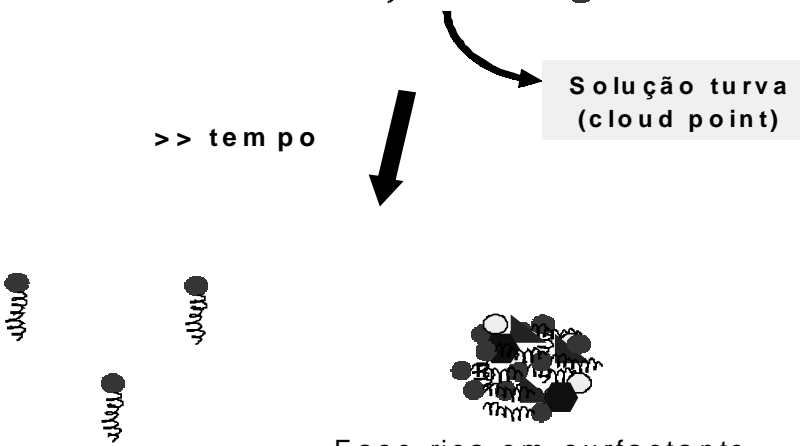

Fase rica em surfactante

Fase diluída de surfactante

$$
<\mathrm{cm} \mathrm{C}
$$

O mecanismo pelo qual a separação ocorre ainda não foi completamente elucidado e gera controvérsias. Alguns autores sugerem que a separação se deve ao aumento no número de agregação micelar (aumento no tamanho das micelas) quando a temperatura é elevada. Outros consideram que o mecanismo de separação de fases ocorre pela mudança na interação micelar, sendo repulsiva em baixas temperaturas e atrativa em temperaturas mais altas. Outros autores têm explicado o fenômeno com base no processo de desidratação que ocorre na camada externa de micelas de surfactantes não-iônicos quando a temperatura é aumentada. A constante dielétrica da água decresce com a elevação da temperatura, formando assim solvente mais pobre para a porção hidrofílica do surfactante (HINZE e PRAMAURO, 1993).

A separação física das fases é facilitada pela diferença de densidade entre as duas fases formadas, pois a rica em surfactante apresenta normalmente maior densidade. Outro fator importante 
é que as temperaturas de ponto nuvem da maioria dos surfactantes são normalmente baixas, entre $20^{\circ} \mathrm{C}$ e $80^{\circ} \mathrm{C}$ para os surfactantes mais comumente empregados (MERINO, RUBIO e BENDITO, 2002).

$\mathrm{Na}$ Tabela 1 são apresentadas algumas temperaturas de formação do ponto nuvem, números de agregação $(\mathrm{N})$, cmc e estruturas dos surfactantes mais empregados nesse processo de extração.

TABELA 1 - ESTRUTURAS E CARACTERÍSTICAS MICELARES DOS SURFACTANTES NÃO-IÔNICOS MAIS COMUNS

\begin{tabular}{|c|c|c|c|}
\hline Classe de surfactantes & $c m c\left(\mathrm{mmol} \mathrm{L}^{-1}\right)$ & $\mathbf{N}$ & $\mathrm{T}\left({ }^{\circ} \mathrm{C}\right)$ \\
\hline \multicolumn{4}{|c|}{$\begin{array}{l}\text { Éteres octilfenóxi polioxietilenados, } \mathrm{OPE}_{x} \\
\mathrm{CH}_{3}\end{array}$} \\
\hline $\mathrm{OPE}_{7-8}($ Triton X-114) & 0,20 & $60-100$ & $23-25$ \\
\hline OPE $_{9-10}($ Triton X-100) & 0,24 & 120 & 65 \\
\hline \multicolumn{4}{|c|}{$\begin{array}{l}\text { Monoéteres de poli(oxietileno glicol), } \mathrm{C}_{i} E_{j} \\
\mathrm{CH}_{3}\left(\mathrm{CH}_{2}\right)_{i-1} \mathrm{O}\left(\mathrm{CH}_{2} \mathrm{CH}_{2} \mathrm{O}\right)_{j} \mathrm{H}\end{array}$} \\
\hline $\mathrm{C}_{12} \mathrm{E}_{4}($ Brij 30) & 0,047 & 40 & $2-7$ \\
\hline $\mathrm{C}_{12} \mathrm{E}_{23}$ (Brij 35) & 0,091 & 40 & $>100$ \\
\hline $\mathrm{C}_{16} \mathrm{E}_{10}($ Brij 56) & 0,0006 & 624 & $64-69$ \\
\hline \multicolumn{4}{|c|}{ Éteres nonilfenílicos polioxietilenados, $N P E_{n}$} \\
\hline $\mathrm{NPE}_{7,5}$ (PONPE-7,5) & 0,085 & - & 5 \\
\hline $\mathrm{NPE}_{10}$ (PONPE-10) & 0,0055 & 100 & $70-72$ \\
\hline
\end{tabular}

$\mathrm{cmc}=$ concentração micelar crítica; $\mathrm{N}$ = número de agregação; $\mathrm{T}$ = temperatura de formação do ponto nuvem.

Os surfactantes não-iônicos do tipo éteres octilfenóxi polioxietilenados (OPE), também conhecidos por Tritons, são os mais empregados pelas suas baixas temperaturas de ponto nuvem $e$ a disponibilidade comercial. O Triton X-114 apresenta a conveniência de separar as fases em temperatura de $25^{\circ} \mathrm{C}$, o que o torna viável para a extração e pré-concentração de compostos de importância ambiental, principalmente agrotóxicos (PINTO, PAVÓN e CORDERO, 1995; MARTINEZ et al., 1996, 2003). Outro surfactante com baixa temperatura de ponto nuvem é o Genapol X-080 (éter monoalquílico de (oxietileno glicol)), muito empregado na extração de agrotóxicos em água (SANZ et al., 2004).

As temperaturas do ponto nuvem de surfactantes podem ser modificadas, monitoradas, ou controladas pela presença de aditivos como, por exemplo, sais, álcalis, ácidos, polímeros, uréia e outros surfactantes. Esses aditivos podem também afetar a eficiência de extração e o fator de préconcentração do processo de extração por ponto nuvem (AL-GHAMDI; NASR-EL-DIN, 1997). 
Apesar de muitas aplicações serem recentes, surpreende a quantidade limitada de trabalhos que investigaram os vários parâmetros experimentais que afetam a eficiência da extração e o fator de pré-concentração do processo de extração por ponto nuvem. FRANKEWICH e HINZE (1994) avaliaram e otimizaram diferentes fatores, $(\mathrm{pH}$, força iônica, hidrofobicidade do surfactante e outros) que afetam o processo de extração e separação de fases do surfactante éter monooctílico de poli (oxietileno glicol), obtendo boas percentagens de recuperação de diversos compostos fenólicos clorados.

\section{PROTOCOLO EXPERIMENTAL}

A técnica por ponto nuvem é bastante simples e não requer equipamentos sofisticados para obtenção de extrações eficientes e elevados fatores de pré-concentração. Inicialmente, o surfactante puro (ou solução concentrada do surfactante) é adicionado à solução aquosa contendo os componentes a serem extraídos e/ou pré-concentrados. A quantidade de surfactante adicionada deve assegurar a formação dos agregados micelares em solução, ou seja, a concentração final do surfactante em solução deve exceder a cmc. Qualquer espécie que se associe e se ligue ao agregado micelar em solução pode ser subseqüentemente extraída em diferentes extensões, dependendo da força da interação da ligação micela-soluto. Em seguida, as condições são alteradas pelo aumento da temperatura, adição de sal ou de outro surfactante para assegurar que a solução micelar seja separada da fase aquosa. A centrifugação pode ser empregada, quando necessário, para acelerar a separação das duas fases. Deve-se, no entanto, tomar cuidado para que a temperatura da solução não seja inferior à do ponto nuvem durante a centrifugação, pois o processo de separação de fases é reversível e abaixo da temperatura do ponto nuvem será obtida novamente uma única fase. Para que a temperatura permaneça acima do valor crítico após a centrifugação, normalmente a solução é aquecida entre $10 \mathrm{e}$ $20^{\circ} \mathrm{C}$ acima do valor crítico. A fase rica em surfactante contendo os componentes extraídos pode ser submetida a tratamento adicional à etapa de quantificação direta (PINTO et al., 1995; FERRER, BELTRÁN e GUITERAS, 1996; FERNÁNDEZ, FERRERA e RODRIGUEZ, 1999; HALKO et al., 2004) (Figura 3).

\section{FIGURA 3 - DIAGRAMA DO PROCEDIMENTO PARA EXTRAÇÃO POR PONTO NUVEM EM AMOSTRAS LÍQUIDAS}

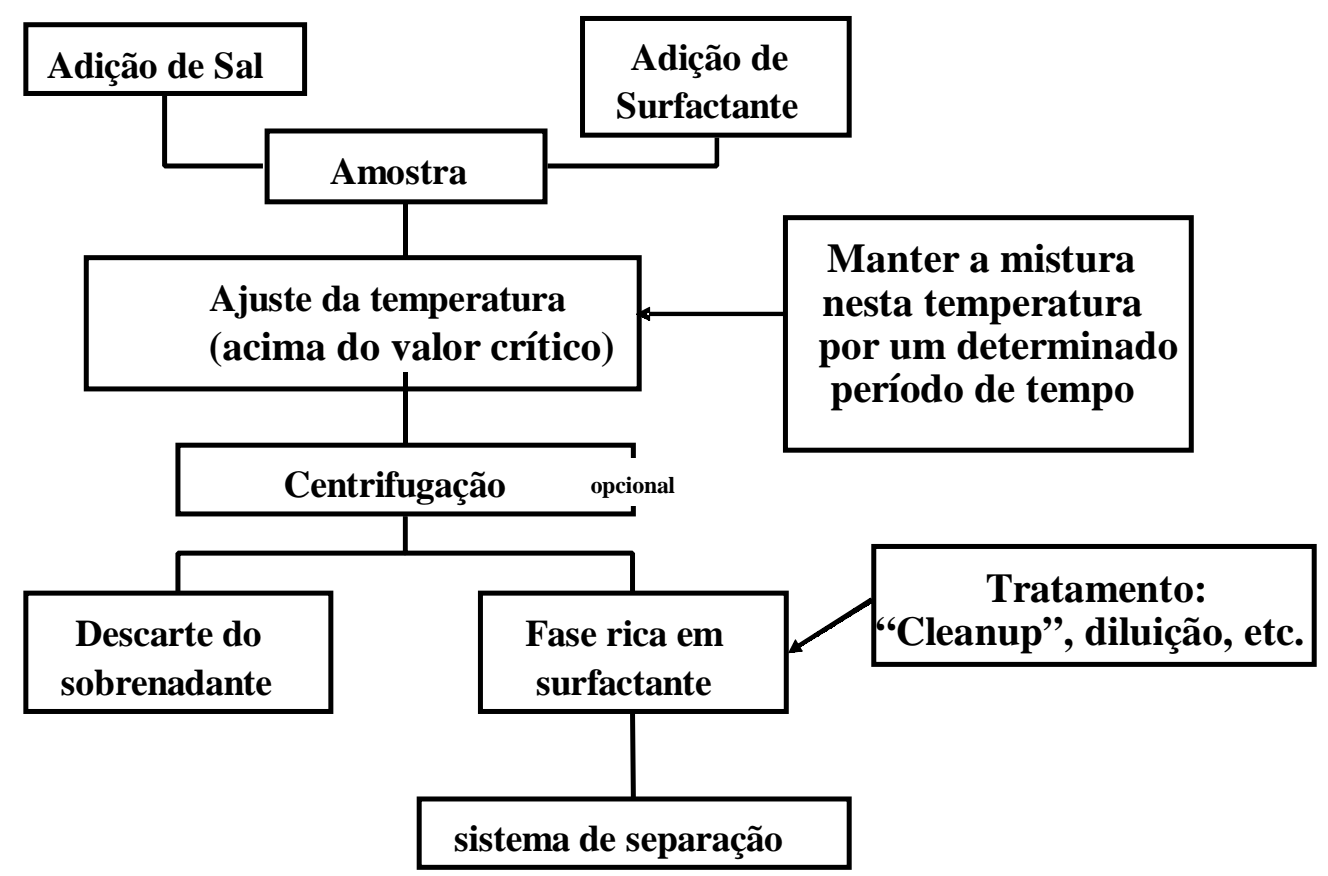


A extração do analito de amostras sólidas acontece de maneira semelhante (Figura 4). Adicionase a solução de surfactante à amostra, deixando a mistura sob agitação branda para contato adequado de forma que ocorra a dessorção do analito da matriz sólida. O emprego de ultra-som pode acelerar esse processo (FERRERA et al., 2004). Após a obtenção do ponto nuvem, a mistura (amostra sólida + solução do surfactante) é submetida à etapa de centrifugação para acelerar a separação das fases. A adição de solução ácida, juntamente com a solução de surfactante na amostra sólida possibilita a formação de três fases após a centrifugação. A fase rica em surfactante ficará no topo, a parte sólida no fundo do tubo, enquanto que a solução ácida contendo o surfactante abaixo da cmc estará entre ambas. Desta forma, obtém-se facilmente a separação da fase rica em surfactante do restante do material (MERINO, RUBIO e BENDITO, 2002). As etapas subseqüentes são as mesmas descritas para as amostras líquidas.

FIGURA 4 - DIAGRAMA DO PROCEDIMENTO PARA EXTRAÇÃO POR PONTO NUVEM EM AMOSTRAS SÓLIDAS

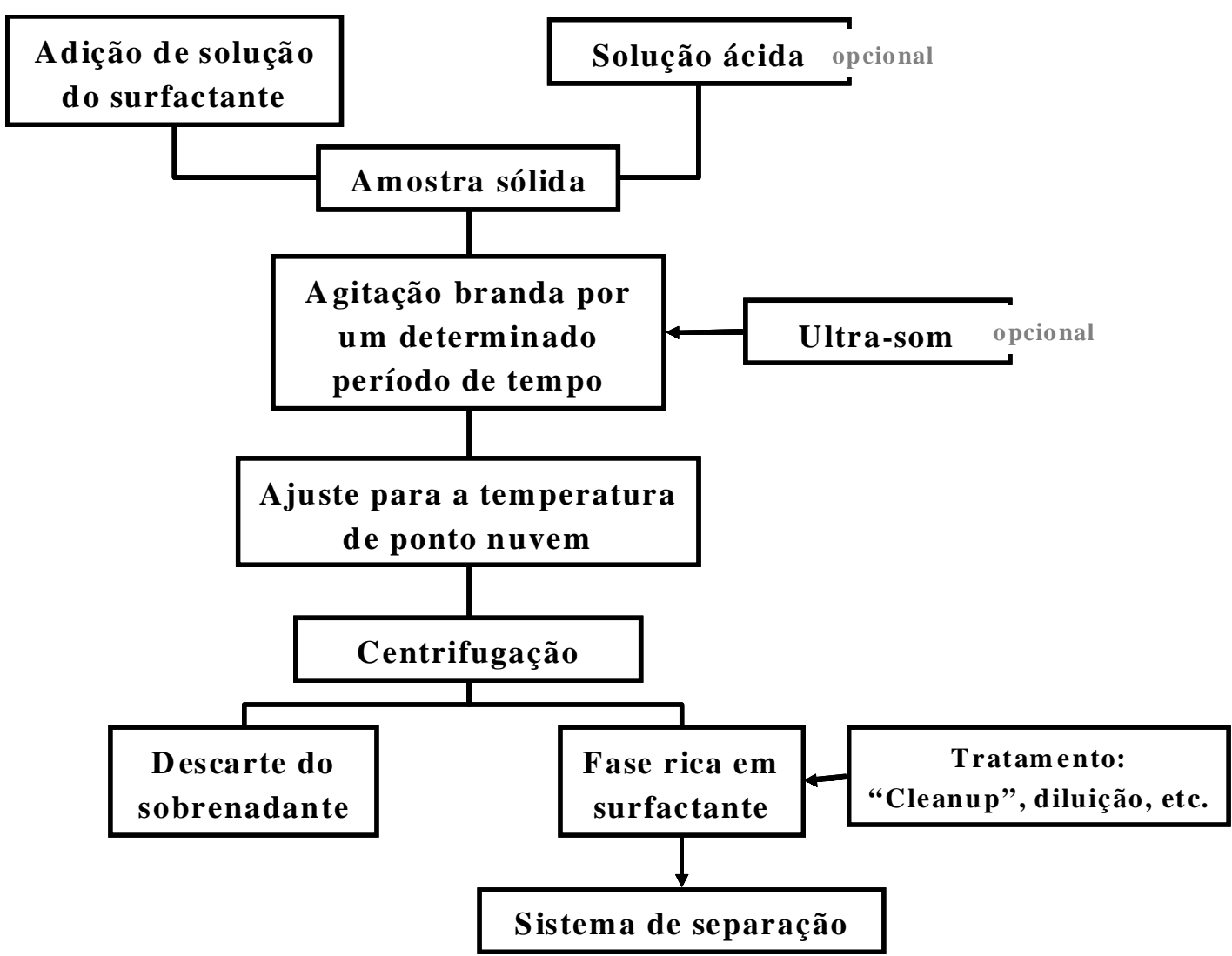

\section{APLICAÇÕES DA TÉCNICA DE EXTRAÇÃO POR PONTO NUVEM}

Historicamente, o procedimento de extração por ponto nuvem foi introduzido e idealizado por WATANABE e TANAKA (1978) que empregaram a técnica na extração de complexos metálicos hidrofóbicos. O escopo da extração por ponto nuvem foi ampliado, pouco depois, por BORDIER (1981) que aplicou a técnica na extração de biomoléculas hidrofóbicas. 
O uso da técnica de extração por ponto nuvem, como etapa de preparo e pré-concentração da amostra que antecede a análise por cromatografia a líquido (PINTO, PAVÓN e CORDEIRO, 1995; HALKO; HUTTA, 2002a,b; DELGADO et al., 2004) ou gás (FRÖSCHL, STANGL e NIESSER, 1997; OHASHI et al., 2004; FARIA et al., 2005) de compostos orgânicos de importância ambiental vem sendo amplamente difundido nos últimos anos. Isto é fruto da intensa busca para desenvolver procedimentos rápidos, simples e eficientes para ensaios ambientais em nível de traço. Além da segurança, da relação custo-benefício, da necessidade de se evitar o uso de grandes quantidades de solventes orgânicos tóxicos e inflamáveis, a técnica de extração por ponto nuvem oferece outras vantagens potenciais sobre os procedimentos que empregam a extração líquido-líquido convencional. Como exemplo tem-se o aumento do limite de detecção do método pelo alto fator de pré-concentração, a eliminação de perdas do analito durante a evaporação de solventes usados na extração líquidolíquido e o enriquecimento do analito na amostra durante o armazenamento (pois o surfactante elimina ou reduz a quantidade do analito sorvido nas paredes de recipientes) permitindo recuperações exatas do analito (MARTINEZ et al., 2000). Essa última vantagem deve-se ao efeito benéfico causado pelos surfactantes durante o armazenamento da amostra. A adsorção nas paredes dos frascos e sua interação com a matéria orgânica são dois problemas que podem resultar em baixas recuperações dos agrotóxicos de amostras de interesse ambiental. Esses problemas podem ser minimizados ou eliminados pela presença do surfactante (PINTO, PAVÓN e CORDEIRO, 1994; QUINA; HINZE, 1999).

O uso de surfactantes não-iônicos nos processos de extração oferece vantagem em relação à toxicidade. Os surfactantes não-iônicos empregados na extração por ponto nuvem, em sua grande maioria, são classificados como não-tóxicos e inofensivos ao homem. Os surfactantes não-iônicos da classe dos polioxietilenados (OPEx e NPEn) são parcialmente biodegradáveis, pois bactérias do gênero Pseudomonas de origem marinha conseguem degradar 4 ou 5 grupos etóxi da cadeia polioxietilenada. A toxicidade para o homem e a biodegradabilidade dos surfactantes são ainda objeto de estudos (SCOTT e JONES, 2000).

Diversos compostos orgânicos vêm sendo estudados mediante extração por ponto nuvem como, por exemplo, agrotóxicos (MARTINEZ et al., 1996; SANZ et al., 2004; HALKO et al., 2004), hidrocarbonetos aromáticos (SICÍLIA et al., 1999; MERINO, RUBIO e BENDITO, 2002; DELGADO et al., 2004), vitaminas (SIRIMANNE et al., 1998), bifenilas policloradas (FRÖSCHL, STANGL e NIESSER, 1997), ácidos húmicos e fúlvicos (REVIA e MAKHARADZE, 1999).

Em razão da necessidade de se utilizar a etapa de pré-concentração no preparo das amostras para as análises de agrotóxicos, normalmente presentes em níveis de traços em amostras reais, a técnica de extração por ponto nuvem tornou-se bastante atrativa.

A determinação de agrotóxicos tanto em água (MARTINEZ et al., 1996; SANZ et al., 2004; HALKO et al., 2004; FARIA et al., 2005) quanto em solo (EVDOKIMOV; WANDRUSZKA, 1998) já foi investigada empregando a extração por ponto nuvem.

Agrotóxicos organofosforados, tais como metil paration, etil paration, paroxon e feniltrotion foram determinados em amostras de água de rio, empregando EPN com o surfactante não-iônico Triton X-114 antes da análise por cromatografia a líquido com detecção eletroquímica (PINTO, PAVÓN e CORDEIRO, 1995). Oito agrotóxicos organofosforados (clorpirifós, diazinon, dimetoato, etoprofós, malation, metidation, paration metílico e paration etílico) empregados na agricultura espanhola foram extraídos de águas residuais e subterrâneas e pré-concentrados pela técnica de extração por ponto nuvem. A cromatografia a líquido com detecção ultravioleta foi a técnica utilizada para a análise dos extratos. Empregando os surfactantes éter laurílico de poli(oxietileno) (POLE) e Genapol X-080, os autores obtiveram recuperações na faixa de 27 a 105\% e fator de pré-concentração de 20 vezes, possibilitando limites de detecção de até $0,03 \mathrm{ng} \mathrm{mL}^{-1}$ (SANZ et al., 2004). Na Tabela 2 estão relacionados os inseticidas organofosforados e outros agrotóxicos cuja análise por cromatografia foi precedida de extração por ponto nuvem. 

POR PONTO NUVEM

\begin{tabular}{|c|c|}
\hline Agrotóxicos & Referência \\
\hline \multicolumn{2}{|l|}{ Inseticidas } \\
\hline $\begin{array}{l}\text { clorpirifós, diazinon, dimetoato, } \\
\text { etoprofós, malation, metidation, } \\
\text { paration metílico, paration etílico, } \\
\text { paraoxon, fenitrotion }\end{array}$ & $\begin{array}{l}\text { (PINTO et al., 1995; SANZ et al., } \\
\text { 2004) }\end{array}$ \\
\hline $\begin{array}{l}\text { DDT, endrin, lindano, aldrin, } \\
\text { clordane, hexaclorocicloexano, } \\
\text { metoxiclor }\end{array}$ & $\begin{array}{l}\text { (KILE e CHLOU, } 1989 ; \\
\text { EVDOKIMOV e WANDRUSZKA, } \\
\text { 1998). }\end{array}$ \\
\hline \multicolumn{2}{|l|}{ Fungicidas } \\
\hline $\begin{array}{l}\text { Carbendazim, benzomil, fuberidazol, } \\
\text { tiabendazol } \\
\text { Folpet, captan, captafol }\end{array}$ & $\begin{array}{l}\text { (STANGL e NIESSNER, 1994; } \\
\text { HALKO et al., 2004) } \\
\text { (MARTINEZ et al., 1996) }\end{array}$ \\
\hline \multicolumn{2}{|l|}{ Herbicidas } \\
\hline $\begin{array}{l}\text { ametrina, terbutrina, } \\
\text { simazina, atrazina, } \\
\text { clortoluron, metoxurona, cloridazon }\end{array}$ & $\begin{array}{l}\text { (MARTINEZ et al., } 1999 ; \\
\text { STANGL, WELLER e NIESSER, } \\
\text { 1995; HALKO e HUTTA, } \\
2002 a, b)\end{array}$ \\
\hline napropamida & $\begin{array}{l}\text { (PRAMAURO e PELIZZETTE } \\
\text { 1988; STINGS e NIESSNER, } \\
\text { 1995) }\end{array}$ \\
\hline 2,4-D e 2,4,5-T & (HINZE et al., 1989) \\
\hline
\end{tabular}

O Genapol X-080 e o POLE foram também empregados na extração de benzimidazol e seus resíduos (benomil, carbendazim, tiabendazol e fuberidazol) em amostras de água. Os extratos foram analisados por cromatografia a líquido com detecção por fluorescência. A eficiência de recuperação dos fungicidas pelo método do ponto nuvem foi comparável à extração em fase sólida (EFS) com recuperações na faixa de $68-98 \%$. O fator de pré-concentração obtido com o método proposto foi de dez vezes, com limite de detecção de $0,004 \mu \mathrm{g} \mathrm{L}^{-1}$ para o fuberidazol, empregando o surfactante POLE em concentração de 4\% (m/v) (HALKO et al., 2004).

Normalmente, a técnica de extração por ponto nuvem emprega baixas concentrações de surfactantes para a extração de agrotóxicos. Em muitos casos é utilizado como surfactante extrator o Triton X-114 pela baixa temperatura de formação do ponto nuvem, maior densidade da fase rica em surfactante comparada à fase aquosa, além do baixo custo e da disponibilidade comercial.

PINTO, PAVÓN e CORDEIRO (1992) empregaram o surfactante Triton X-114 na extração de paration e de vitaminas $A$ e $E$ de água. Os autores estudaram o processo de extração na faixa de concentração de 1 a $5 \%$ (m/v) para o Triton X-114. Os valores otimizados foram de 1,3\% (m/v) para a extração das vitaminas e de $1,0 \%(\mathrm{~m} / \mathrm{v})$ para o paration. Os compostos foram quantificados por cromatografia a líquido com detecção eletroquímica. Em outro estudo, PINTO, PAVÓN e CORDEIRO (1995) empregaram a mesma metodologia na determinação de quatro agrotóxicos organofosforados (paraoxon, paration metílico, paration etílico e fenitrotion) em amostras de água de rio. A eficiência de extração ficou próxima a 100\% para todos os inseticidas com limites de detecção na faixa de 0,18 a 
0,35 $\mathrm{g} \mathrm{L}^{-1}$. MARTINEZ et al. (1996) descreveram método, baseado na extração por ponto nuvem, para a determinação dos fungicidas folpet, captan e captafol em amostras de água de rio, usando sistema de cromatografia a líquido com detecção eletroquímica. Empregaram concentração de 0,25\% (m/v) de Triton X-114 e obtiveram fator de pré-concentração de até 78 vezes com recuperações entre 76 e $106 \%$ e limites de detecção de aproximadamente $4 \mu \mathrm{g} \mathrm{L}^{-1}$.

A extração de agrotóxicos de amostras sólidas pela técnica do ponto nuvem ainda é muito pouco explorada, apesar de outras classes de compostos terem sido eficientemente extraídas ( $\mathrm{CHOI}$ et al., 2003; MARTINEZ et al., 2003).

EVDOKIMOV e WANDRUSKA (1998) propuseram a mistura de surfactantes (Igepal ICO-630 e Triton X-114) para a extração de DDT de solos poluídos. Obtiveram recuperações superiores a 83\% quando os solos poluídos foram tratados por duas horas com a mistura a $3 \%(\mathrm{~m} / \mathrm{v})$ dos surfactantes. Método bastante eficiente para extração por ponto nuvem de tiabendazol e napropamida de solos foi desenvolvido por STANGL e NIESSNER (1994) com quantificação dos extratos por cromatografia a líquido e detecção por fluorescência. Mais de $95 \%$ dos resíduos dos agrotóxicos foram extraídos com Genapol X-080 da amostra de solo, com limites de detecção abaixo de $0,2 \mu \mathrm{g} \mathrm{L}^{-1}$. O método foi aplicado também na extração desses mesmos agrotóxicos em águas.

A maioria dos trabalhos empregando a extração por ponto nuvem na determinação de agrotóxicos utiliza como técnica de análise a cromatografia a líquido de alta eficiência. Apesar de vários trabalhos usarem a extração por ponto nuvem associada com a cromatografia a gás (FRÖSCHL, STANGL e NIESSER, 1997) e com eletroforese capilar (TANG, JIANG e YAN, 2004), a análise de resíduos de agrotóxicos por essas técnicas foi pouco explorada.

MARTÍNEZ et al. (1999) empregaram a metodologia do ponto nuvem na extração e préconcentração de herbicidas triazinas antes da análise por eletroforese capilar por zona. Seis triazinas foram extraídas de águas de rios e água bruta por Triton X-114 a $0,25 \%(\mathrm{~m} / \mathrm{v})$ com eficiência de extração próxima a 100\%. FARIA et al. (2005) usaram Triton X-114 a 1,0\% (m/v) para a extração e préconcentração do inseticida organofosforado dissulfoton de amostras de águas, com quantificação por cromatografia a gás e detecção por ionização em chama (CG-DIC). A eficiência de recuperação obtida para o dissulfoton aproximou-se de 100\% com fator de pré-concentração de 40 vezes. O limite de detecção para o método proposto foi de $47 \mu \mathrm{g} \mathrm{L}^{-1}$.

A principal dificuldade em associar a extração por ponto nuvem à cromatografia a gás ou à eletroforese capilar é a necessidade de remoção do surfactante do extrato antes da injeção cromatográfica ou eletroforética. Na cromatografia a gás, a injeção direta do extrato contendo 0 surfactante pode deteriorar a coluna levando-a ao entupimento (HINZE e PRAMAURO, 1993; QUINA e HINZE, 1999). Isso inutiliza a coluna cromatográfica, pois os surfactantes apresentam altos pontos de ebulição, normalmente superiores a $300^{\circ} \mathrm{C}$. Na eletroforese capilar, a injeção direta do material extraído pode provocar a adsorção do surfactante às paredes internas do tubo capilar de sílica fundida. Tal fato provoca acentuada perda de eficiência e reprodutibilidade do tempo de migração e das áreas dos picos eletroforéticos (MARTINEZ et al., 1999). Contudo, esses problemas podem ser contornados com a remoção do surfactante do extrato. Em muitas outras aplicações envolvendo a extração por ponto nuvem é necessário separar o surfactante do material extraído (QUINA e HINZE, 1999; MARTINEZ et al., 2000). Diferentes sistemas têm sido desenvolvidos com esse propósito, dependendo sobretudo do objetivo e/ou subseqüente utilização do material a ser recuperado. Por exemplo, quando a extração por ponto nuvem é utilizada no preparo da amostra para análise por cromatografia a líquido com detecção por absorção ultravioleta (UV), o surfactante pode interferir na detecção do analito. Os surfactantes não-iônicos do tipo alquilfenóis polioxietilenados $\left(O P E_{x}\right.$ e NPE $\left.{ }_{n}\right)$ absorvem na região do UV e o pico de absorvância pode ocultar o pequeno sinal do analito de interesse (MARTINEZ et al., 1996; PINTO, PAVÓN e CORDEIRO, 1992).

A maioria dos surfactantes não-iônicos é, provavelmente, melhor extraída com solventes mais polares ou pela mistura de solventes polares. O método mais comum e mais fácil de remover o 
surfactante é a diálise (ROJO et al., 1997). Esse método, simples e eficaz para surfactantes com valor de $\mathrm{cmc}$ relativamente alto (acima de $1 \mathrm{mmol} \mathrm{L}^{-1}$ ), é muito empregado para a remoção da maioria dos surfactantes zwitteriônicos. Porém, a diálise é ineficiente na remoção de surfactantes não-iônicos com baixos valores de cmc. Para tais surfactantes, o contato com resinas sintéticas como a BioBeads SM2 (material copolimérico com afinidade para surfactantes do tipo Triton) (ROJO et al., 1997) mostrou-se eficiente. O surfactante não-iônico pode ser removido também pela eluição através de colunas contendo materiais adsorventes como a hidroxiapatita (QUINA e HINZE, 1999), sílica-gel (FERRER, BELTRÁN e GUITERAS, 1996), Florisil (FRÖSCHL, STANGL e NIESSER, 1997) ou pela combinação desses (FARIA et al., 2005), bem como mediante precipitação do surfactante na fase micelar com solvente apropriado, seguido de filtração e recuperação da parte filtrada (SIRIMANNE et al., 1996).

\section{CONCLUSÃO E PERSPECTIVAS}

O uso da extração por ponto nuvem para a separação e pré-concentração de compostos orgânicos já está estabelecido como alternativa aos métodos convencionais. Suas características analíticas são, na maioria dos casos, melhores que as dos métodos de extração convencionais. Os resultados obtidos com os métodos propostos para a extração de agrotóxicos por ponto nuvem indicam que essa técnica oferece diversas vantagens altamente interessantes sob o ponto de vista analítico. Uma delas envolve a possibilidade de extração e pré-concentração de compostos com diferentes polaridades (diferentes classes de agrotóxicos) numa única etapa. O fator de pré-concentração pode ser otimizado pela modificação do tipo e da concentração do surfactante, bem como as condições experimentais sob as quais a separação de fases e a extração são realizadas. Além disso, os surfactantes mais freqüentemente usados estão disponíveis comercialmente, sendo menos tóxicos e mais baratos que os solventes tradicionais. Outra característica é o fato de evitar a etapa de evaporação dos solventes e, portanto, nenhum composto será perdido nesse processo. As operações experimentais envolvidas na metodologia do ponto nuvem são muito simples e a fase rica em surfactante é compatível com as fases móveis empregadas na cromatografia a líquido de alta eficiência.

Apesar dos avanços obtidos até o momento será necessário estudar em maior profundidade as aplicações dessa metodologia na extração de agrotóxicos de amostras de solo, folhas e frutos. Novos estudos também devem ser conduzidos para ampliar o campo de aplicação da extração por ponto nuvem para a eletroforese capilar em meio orgânico, eletrocromatografia e cromatografia a gás com detecção por espectrometria de massas. Sugere-se ainda como campo de investigação em potencial a automação da técnica de extração por ponto nuvem e seu acoplamento on-line com o sistema de operação.

\section{Abstract}

\section{CLOUD POINT EXTRACTION: AN ALTERNATIVE TECHNIQUE TO THE EXTRACTION OF PESTICIDE RESIDUES}

This work presents a brief review of aqueous surfactant solutions application (cloud point extraction) for extraction and the preconcentration of pesticides as a promising alternative to the conventional extraction techniques. The fundamentals of cloud point extraction as well as its solubilization capabilities for organic compounds and the experimental protocol for pesticide extraction from different matrices are described. Practical problems and perspectives of this technique when employed as a step prior to the determinations via chromatographic or electrophoretic techniques are also approached. In spite of the progresses obtained until the moment it will be necessary to study in larger depth the applications of that methodology in pesticides extraction of soil, leaves and fruits samples. New studies should also be conducted to enlarge the application field of cloud point extraction capillary electrophoresis in organic media, electro-chromatography and gas chromatography coupled to mass spectrometry. It still suggests as potential investigation field the automation of the cloud point extraction technique and its on-line monitoring with the operation system.

KEY-WORDS: CLOUD POINT EXTRACTION; PESTICIDES; EXTRACTION TECHNIQUES. 


\section{REFERÊNCIAS}

1 AL-GHAMDI, A. M.; NASR-EL-DIN, H. A. Effect of oilfield chemicals on the cloud point of nonionic surfactants. Colloid Surface A, v. 125, p. 5-18, 1997.

2 BORDIER, C. Phase Separation of integral membrane proteins in Triton X-114 solution. J. Biol. Chem., v.256, p.1604-1607, 1981.

3 CHOI, M. P. K.; CHAN, K. K. C.; LEUNG, H. W.; HUIE, C. W. Pressurized liquid extraction of active ingredients (ginsenosides) from medicinal plants using non-ionic surfactant solutions. J. Chromatogr. A, v. 983, p. 153162, 2003.

4 DELGADO, B.; PINO, V.; AYALA, J. H.; GONZALEZ, V.; AFONSO, A. M. Nonionic surfactant mixtures: a new cloud-point extraction approach for the determination of PAHs in seawater using HPLC with fluorimetric detection. Anal. Chim. Acta, v. 518, p. 165-172, 2004.

5 DERYABINA, M. A.; YAKOVLEVA, Y. N.; POPOVA, V. A.; ERERNIN, S. A. Determination of the herbicide acetochlor by fluorescence polarization immunoassay. J. Anal. Chem., v. 60, p. 80-85, 2005.

6 EVDOKIMOV, E.; von WANDRUSZKA, R. Decontamination of DDT-polluted soil by soil washing cloud point extraction. Anal. Lett., v. 31, p. 2289-2298, 1998.

7 FARIA, A. M.; QUEIROZ, M. E. L. R.; NEVES, A. A.; LIMA, C. F.; DARDENGO, R. P. Determination of disulfoton in water samples by cloud point extraction and gas chromatography. Talanta, 2005. No prelo.

8 FERNÁNDEZ, A. E.; FERRERA, Z. S.; RODRIGUEZ, J. J. S. Application of cloud-point methodology to the determination of polychlorinated dibenzofurans in sea water by high-performance liquid chromatography. Analyst, v. 124, p. 487-491, 1999.

9 FERRER, R.; BELTRÁN, J. L.; GUITERAS, J. Use of cloud point extraction methodology for the determination of $\mathrm{PAH}$ priority pollutants in water samples by high-performance liquid chromatography with fluorescence detection and wavelength programming. Anal. Chim. Acta, v. 330, p. 199-206, 1996.

10 FERRERA, Z. S.; SANZ, C. P.; SANTANA, C. M.; RODRIGUEZ, J. J. S. The use of micellar systems in the extraction and pre-concentration of organic pollutants in environmental samples. Trends Anal. Chem., v. 23, p. 479-489, 2004.

11 FRANKEWICH, R. P.; HINZE, W. L. Evaluation and optimization of the factors affecting nonionic surfactantmediated phase separations. Anal. Chem., v. 66, p. 944-954, 1994.

12 FRÖSCHL, B.; STANGL, G.; NIESSNER, R. Combination of micellar extraction and GC-ECD for the determination of polychlorinated biphenyls (PCBs) in water. Fresenius J. Anal. Chem., v. 357, p. 743-746, 1997.

13 HALKO, R.; HUTTA, M. Cloud point extraction and high-performance liquid chromatographic determination of selected herbicides. Fresenius Environ. Bull., v. 11, p. 22-26, 2002a.

14 HALKO, R.; HUTTA, M. Study of high-performance liquid chromatographic separation of selected herbicides by hydro-methanolic and micellar liquid chromatography using Genapol X-080 non-ionic surfactant as mobile phase constituent. Anal. Chim. Acta, v. 466, p. 325-333, 2002b.

15 HALKO, R.; SANZ, C. P.; FERRERA, Z. S.; RODRIGUEZ, J. J. S. Determination of benzimidazole fungicides by HPLC with fluorescence detection after micellar extraction. Chromatographia, v. 60, p. 151-156, 2004.

16 HINZE, W. L.; PRAMAURO, E. A critical review of surfactant-mediated phase separations (cloud-point extractions): theory and applications. Crit. Rev. Anal. Chem., v. 24, p. 133-177, 1993.

17 HINZE, W. L.; SINGH, H. N.; FU, Z. F.; WILLIAMS, R.; KIPPENBERGER, D. J.; MORRIS, M. D.; SADEK, F. S. Micellemediated methodologies for the preconcentration and separation of polycyclic aromatic compounds. In: VO DINH, T. (Ed.). Chemical analysis of polycyclic aromatic compounds. New York: Wiley, 1989. Chap. 5.

18 KILE, D. E.; CHLOU, C. T. Water solubility enhancements of DDT and trichlorobenzene by some surfactants below and above the critical micelle concentration. Environ. Sci. Technol., v. 23, p. 832-838, 1989.

19 KOVAI, N.; PROSEN, H.; ZUPANI-KRALJ, L. Determination of triazines and atrazine metabolites in soil by microwaveassisted solvent extraction and highpressure liquid chromatography with photo-diode-array detection. Acta Chim. Slov., v. 51, p. 395-407, 2004.

20 MAHARA, B. M.; BOROSSAY, J.; TORKOS, K. Liquid-liquid extraction for sample preparation prior to gas chromatography and gas chromatography mass spectrometry determination of herbicide and pesticide compounds. Microchem. J., v. 58, p. 31-38, 1998.

21 MARTÍNEZ, R. C.; GONZALO, E. R.; JIMÉNEZ, M. G. G.; PINTO, C. G.; PAVÓN, J. L. P.; MÉNDEZ, J. H. Determination of the fungicides folpet, captan and captafol by cloud-point preconcentration and high-performance liquid 
chromatography with electrochemical detection. J. Chromatogr. A, v. 754, p. 85-96, 1996.

MARTíNEZ, R. C.; GONZALO, E. R.; ALVAREZ, J. D.; MÉNDEZ, J. H. Cloud point extraction as a preconcentration step prior to capillary electrophoresis. Anal. Chem., v. 71, p. 2468-2474, 1999.

23 MARTíNEZ, R. C.; GONZALO, E. R.; CORDERO, B. M.; PAVÓN, J. L. P.; PINTO, C. G.; LAESPADA, E. F. Surfactant cloud point extraction and preconcentration of organic compounds prior to chromatography and capillary electrophoresis. J. Chromatogr. A, v. 902, p. 251-265, 2000.

24 MARTíNEZ, R. C.; GONZALO, E. R.; ÁLVAREZ, J. D.; PINTO, C. G.; MÉNDEZ, J. H. Prediction of the behaviour of organic pollutants using cloud point extraction. J. Chromatogr. A, v. 1005, p. 23-34, 2003.

25 McINTIRE, G. L. Micelles in Analytical Chemistry. Crit. Rev. Anal. Chem., v. 21, p. 257-278, 1990.

26 MERINO, F.; RUBIO, S.; BENDITO, D. P. Acid-induced cloud point extraction and preconcentration of polycyclic aromatic hydrocarbons from environmental solid samples. J. Chromatogr. A, v. 962, p. 1-8, 2002.

27 OHASHI, A.; OGIWARA, M.; IKEDA, R.; OKADA, H.; OHASHI, K. Cloud point extraction and preconcentration for the gas chromatography of phenothiazine tranquilizers in spiked human serum. Anal. Sci., v. 20, p. 1353-1357, 2004.

28 PINTO, C. G.; PAVÓN, J. L. P.; CORDERO, B. M. Cloud point preconcentration and high-performance liquidchromatographic analysis with electrochemical detection. Anal. Chem., v. 64, p. 2334-2338, 1992.

29 PINTO, C. G.; PAVÓN, J. L. P.; CORDERO, B. M. Cloud point preconcentration and high-performance liquid chromatographic determination of polycyclic aromatic hydrocarbons with fluorescence detection. Anal. Chem., v. 66, n. 6 , p. $874-881,1994$.

30 PINTO, C. G.; PAVÓN, J. L. P.; CORDERO, B. M. Cloud point preconcentration and high-performance liquid chromatographic determination of organophosphorous pesticides with dual electrochemical detection. Anal. Chem., v. 67, p. 2606-2612, 1995.

31 PRAMAURO, E.; PELIZZETTI, E. Micelles: a new dimension in analytical chemistry. Trends Anal. Chem., v. 7, p. $260.272,1988$

32 QUINA, F. H.; ALONSO, E. O.; FARAH, J. P. S. Incorporation of nonionic solutes into aqueous micelles: a linear solvation free energy relationship analysis. J. Phys. Chem., v. 99, p. 11708-11714, 1995.

33 QUINA, F. H.; HINZE, W. L. Surfactant-mediated cloud point extractions: an environmentally benign alternative separation approach. Ind. Eng. Chem. Res., v. 38, p. 4150-4168, 1999.

34 REVIA, R. L.; MAKHARADZE, G. A. Cloud-point preconcentration of fulvic and humic acids. Talanta, v.48, p.409413, 1999.

35 ROJO, M.; BUDIN, N.; KELLNER, R.; GRUENBERG, J. Generation of proteoliposomes from subcellular fractions. Electrophoresis, v. 18, p. 2620-2628, 1997.

36 SANZ, C. P.; HALKO, R.; FERRERA, Z. S.; RODRÍGUEZ, J. J. S. Micellar extraction of organophosphorus pesticides and their determination by liquid chromatography. Anal. Chim. Acta, v. 524, p. 265-270, 2004.

37 SCORZA JÚNIOR, R. P.; RIGITANO, R. L. O.; LIMA, L. A.; GOUVÊA, A. V. Avaliação de dois simuladores para a predição da lixiviação de sulfona de aldicarbe em um latossolo vermelho-amarelo. Pesquisa Agropecuária Brasileira, v. 35, n. 2, p. 241-250, 2000.

38 SCOTT, M. JÚNIOR; JONES, M. N. The biodegradation of surfactants in the environment. Biochim. Biophys. Acta, v. 1508, p. 235-251, 2000.

39 SICILIA, D.; RUBIO, S.; BENDITO, D. P.; MANIASSO, N.; ZAGATTO, E. A. G. Anionic surfactants in acid media: a new cloud point extraction approach for the determination of polycyclic aromatic hydrocarbons in environmental samples. Anal. Chim. Acta. v. 392, p. 29-38, 1999.

40 SIRIMANNE, S. R.; BARR, J. R.; PATTERSON JR, D. G.; MA, L. Quantification of polycyclic aromatic hydrocarbons and polychlorinated dibenzo-p-dioxins in human serum by combined micelle-mediated extraction (cloud-point extraction) and HPLC. Anal. Chem., v. 68, p. 1556-1560, 1996.

41 SIRIMANNE, S. R.; PATTERSON, D. G.; MA, L.; JUSTICE, J. B. Application of cloud-point extraction-reversedphase high-performance liquid chromatography - A preliminary study of the extraction and quantification of vitamins A and E in human serum and whole blood. J. Chromatogr. B, v. 716, p. 129-137, 1998.

42 STANGL, G.; NIESSNER, R. Cloud point extraction of napropamide and thiabendazole from water and soil. Mikrochim. Acta, v. 113, p. 1-8, 1994.

43 STANGL, G.; WELLER, M. G.; NIESSNER, R. Increased sensibility and selectivity of an enzyme-linked immunosorbent 
assay for the determination of atrazine by use of nonionic surfactants. Fresenius J. Anal. Chem., v. 351, p. 301-304, 1995.

44 STINGS, G.; NIESSNER, R. Micellar extraction: a new step for enrichment in the analysis of Napropamide. Int. J. Environ. Anal. Chem., v. 58, p. 15-22, 1995.

45 TANG, A. N.; JIANG, D. Q.; YAN, X. P. Cloud point extraction preconcentration for capillary electrophoresis of metal ions. Anal. Chim. Acta, v. 507, p. 199-204, 2004.

46 WATANABE, H.; TANAKA, H. A nonionic surfactant as a new solvent for liquid-liquid extraction of zinc (II) with 1-(2-pyridylazo)-2-naphthol. Talanta, v. 25, p. 585-589, 1978.

47 XU, P. X.; YUAN, D. X.; DENG, Y. Z.; LI, Q. L. Determination of trace organophosphorus pesticides in water samples by membrane extraction and gas chromatography. Chinese J. Anal. Chem., v. 30, p. 321-323, 2002.

48 ZHU, L. Y.; EE, K. H.; ZHAO, L. M.; LEE, H. K. Analysis of phenoxy herbicides in bovine milk by means of liquidliquid-liquid microextraction with a hollow-fiber membrane. J. Chromatogr. A, v. 963, p. 335-343, 2002.

\section{AGRADECIMENTOS}

Os autores agradecem à Capes (Coordenação e Aperfeiçoamento de Pessoal de Nível Superior) e à Fapemig (Fundação de Amparo à Pesquisa do Estado de Minas Gerais) pelo fomento à pesquisa, e ao Prof. Kenneth E. Collins pela revisão do inglês. 